\title{
First Report of an Extensively Drug-Resistant ST23 Klebsiella pneumoniae of Capsular Serotype K1 Co-Producing CTX-M-15, OXA-48 and ArmA in Spain
}

\author{
Marta Hernández ${ }^{1} \mathbb{1}$, Luis López-Urrutia ${ }^{2} \mathbb{D}$, David Abad ${ }^{1}{ }^{\mathbb{D}}$, \\ Mónica De Frutos Serna ${ }^{2} \mathbb{D}$, Alain A. Ocampo-Sosa ${ }^{3, * \mathbb{D}}$ and José María Eiros ${ }^{2}$ \\ 1 Laboratorio de Biología Molecular y Microbiología, Instituto Tecnológico Agrario de Castilla y \\ León (ITACyL), 47071 Valladolid, Spain; hernandez.marta@gmail.com (M.H.); AbaGarDa@itacyl.es (D.A.) \\ 2 Servicio de Microbiología, Hospital Universitario del Río Hortega, 47012 Valladolid, Spain; \\ llopezu@saludcastillayleon.es (L.L.-U.); mdefrutossernad@saludcastillayleon.es (M.D.F.S.); \\ jmeiros@saludcastillayleon.es (J.M.E.) \\ 3 Laboratorio de Microbiología Clínica y Molecular, Instituto de Investigación Sanitaria Marqués de \\ Valdecilla (IDIVAL), 39011 Santander, Spain \\ * Correspondence: alainocampo1971@gmail.com; Tel.: +34-942-944-382
}

check for updates

Citation: Hernández, M.; López-Urrutia, L.; Abad, D.; De Frutos Serna, M.; Ocampo-Sosa, A.A.; Eiros, J.M. First Report of an Extensively Drug-Resistant ST23 Klebsiella pneumoniae of Capsular Serotype K1 Co-Producing CTX-M-15, OXA-48 and ArmA in Spain. Antibiotics 2021, 10, 157. https:// doi.org/10.3390/antibiotics10020157

Academic Editor: Maria Mezzatesta Received: 13 January 2021

Accepted: 1 February 2021

Published: 4 February 2021

Publisher's Note: MDPI stays neutral with regard to jurisdictional claims in published maps and institutional affiliations.

Copyright: (c) 2021 by the authors. Licensee MDPI, Basel, Switzerland. This article is an open access article distributed under the terms and conditions of the Creative Commons Attribution (CC BY) license (https:/ / creativecommons.org/licenses/by/ $4.0 /)$.

\begin{abstract}
An extensively drug-resistant (XDR) Klebsiella pneumoniae isolate MS3802 from a tracheostomy exudate was whole-genome sequenced using MiSeq and Oxford Nanopore MinION platforms in order to identify the antimicrobial resistance and virulence determinates and their genomic context. Isolate MS3802 belonged to the clone ST23 and presented a capsular serotype K1, associated with hypervirulent K. pneumoniae (hvKp) isolates. The isolate harboured a chromosomally encoded $b l a_{\mathrm{CTX}-\mathrm{M}-15}$ gene and contained a large IncHI1B hybrid virulence/resistance plasmid carrying another copy of the bla $a_{\mathrm{CTX}-\mathrm{M}-15}$ and the virulence factors iuc $A B C D$-iut $A$, iroBCDN, rmp $A$ and $r m p A 2$. The carbapenemase gene $b l a_{\mathrm{OXA}-48}$ was found in a Tn1999-like transposon and the 16S rRNA methylase armA gen located in the vicinity of other antibiotic-resistant genes on an IncM2

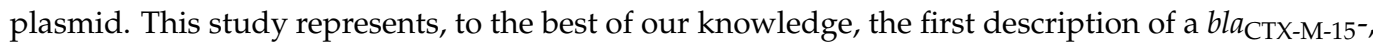
bla $a_{\mathrm{OXA}-48^{-}}$and armA-harbouring K. pneumoniae of ST23 and capsular serotype K1 in Spain. Our report emphasizes the importance of implementing new surveillance strategies to monitor the risk of emergence and spread of such XDR and hypervirulent K. pneumoniae isolates.
\end{abstract}

Keywords: Klebsiella pneumoniae; OXA-48; CTX-M-15; ArmA; hybrid virulence/resistance plasmids; extensively drug-resistant; hypervirulent Klebsiella pneumoniae

\section{Introduction}

Klebsiella pneumoniae is one of the most significant opportunistic human pathogens. This Gram-negative bacterium is responsible for hospital- and community-acquired infections such as urinary tract infections, pneumonia and severe bacteremia, associated with high morbidity and mortality rates [1]. A new "hypervirulent" K. pneumoniae (hvKp), which differed from the classical K. pneumoniae (cKp) by showing a hypermucoviscous phenotype, was described for the first time more than 20 years ago in Taiwan [2]. Since then several new cases have been reported in different regions of Europe and America, but the most important outbreaks have occurred in Asian countries [3]. In our country, some hvKp have also been documented [4-6]. hvKp strains can cause severe infections, such as pyogenic liver abscesses (PLA), osteomyelitis, endophthalmitis and metastatic meningitis in healthy individuals [7]. The hypermucoviscous/hypervirulent phenotype is generally associated with the $\operatorname{mag} A(w z y-\mathrm{K} 1)$ gene, present in the gene cluster for K1 capsular polysaccharide $[7,8]$, and/or $\operatorname{rmp} A$, the regulator of mucoid phenotype A, which activates capsule production and may be located in the chromosome or a large virulence plasmid of both hvKp K1 and K2 capsular phenotypes $[9,10]$. However, not all hvKp 
strains show a hypermucoviscous phenotype as defined by a positive string test [11], nor the presence of the $\mathrm{K} 1$ or $\mathrm{K} 2$ capsule by itself can be used to define a strain as hvKp [12]. On the other hand, there are several other virulence factors associated with hypervirulent $\mathrm{K} 1$ and $\mathrm{K} 2$ phenotypes such as the siderophores aerobactin and yersiniabactin, the iron uptake operon, $k f u$, the fimbrial gene cluster, $k p c$, and alls, related to allantoin metabolism, just to mention a few [13].

At least 134 capsular serotypes have been described so far [14], but most of the hvKp strains belong to serotype K1, followed to a lesser extent by serotypes K2, K5 and K57 [13,15]. According to multilocus sequence typing (MLST) and core genome MLST (cgMLST) analyses, the majority of hvKp strains of serotype K1 are confined within the clonal complex CC23 that includes sequence types ST23, ST26, ST57 and ST1633, which are associated with specific virulence factors that confer the hypervirulent phenotype and perhaps also an increased bacterial fitness. While, hvKp strains of serotype K2 can be found in a variety of unrelated sequence types, including ST25, ST65, ST66 and ST86, and are genetically more diverse [13,15-17].

Generally, hvKp are highly susceptible to most commonly used antimicrobial agents, with the exception of ampicillin [18]. However, this scenario seems to be changing over time with the global spread of genetic mobile elements and conjugative plasmid carrying several antibiotic resistance determinants [15]. Multidrug-resistant hvKp (MDR-hvKp), including extended-spectrum $\beta$-lactamases (ESBL)-producing isolates and carbapenemresistant hvKp (CR-hvKp), have been described recently [19-26]. MDR and/or carbapenemresistant cKp (CR-cKp) isolates have also the capacity to acquire virulence plasmids such as pLVPK [27] or pK2044 [28], thus becoming hvKp [29].

In this study, we reported the first isolation of an XDR-K. pneumoniae isolate of sequence type 23 (ST23) and capsular serotype K1 co-producing OXA-48, CTX-M-15 and ArmA from a tracheostomy exudate sample collected in a Spanish hospital.

\section{Results and Discussion}

\subsection{Isolation and Phenotypic Tests of K. pneumoniae MS3802}

The MS3802 isolate was originally recovered from a tracheostomy exudate sample from a male patient who was hospitalized due to injuries caused by a motor vehicle accident. The isolate was identified as K. pneumoniae by using both a Vitek-2 instrument and matrix-assisted laser desorption ionization - time of flight mass spectrometry (MALDITOF MS). The MS3802 isolate was classified as XDR according to standard definitions for acquired resistance [30]. MS3802 was non-susceptible to most of the antibiotics tested, remaining only sensitive to imipenem, meropenem, doripenem and tetracycline (Table 1). Management of hvKp infections is more difficult due to the appearance of MDR or XDR phenotypes. However, in spite of being XDR, isolates like MS3802 that still remain susceptible to few antibiotics may be treated at least with a carbapenem. MS3802 did not show a hypermucoviscous phenotype, as the string test was negative (colonies did not stretch more than $5 \mathrm{~mm}$ using a standard bacteriological loop) and was considered as mucoid. A hypermucoviscous phenotype is usually associated with hvKp. However, not all the hvKp isolates are positive to the string test. For that reason, hypervirulence must be defined by the presence of certain virulence factors such as aerobactin, yersiniabactin and the $r m p A / r m p A 2$ genes associated with this phenotype, as well as the clinical manifestations of the disease [12]. Rapid identification of K. pneumoniae capsular serotypes K1 and K2 usually associated with hvKp may also be carried out by immunochromatographic strip assays [31] or PCR [23]. 
Table 1. Antimicrobial susceptibility profiles of the Klebsiella pneumoniae isolate MS3802 and Escherichia coli J53 transconjugants with the plasmid pMS3802OXARMA.

\begin{tabular}{|c|c|c|c|c|}
\hline \multirow[b]{2}{*}{ Antimicrobial Agent } & \multicolumn{4}{|c|}{ MIC $(\mu \mathrm{g} / \mathrm{mL})$} \\
\hline & $\begin{array}{c}\text { K. pneumoniae } \\
\text { MS3802 }\end{array}$ & E. coli J53-Pip ${ }^{\mathrm{r}}$ & E. coli $\mathrm{J} 53-\mathrm{AK}^{\mathrm{r}}$ & E. coli $\mathrm{J} 53(\mathrm{wt})$ \\
\hline Ampicillin & $>128(\mathrm{R})$ & $>128$ & $>128(\mathrm{R})$ & $64(\mathrm{R})$ \\
\hline Ampicillin/Sulbactam & $>64(\mathrm{R})$ & $>64$ & $>64(\mathrm{R})$ & $64(\mathrm{R})$ \\
\hline Amoxicillin/Clavulanic acid & $>128(\mathrm{R})$ & $>128(\mathrm{R})$ & $>128(\mathrm{R})$ & $8(S)$ \\
\hline Aztreonam & $>128(\mathrm{R})$ & $<0.125(\mathrm{~S})$ & $<0.125(S)$ & $0.125(S)$ \\
\hline Piperacillin/tazobactam & $>128(\mathrm{R})$ & $128(\mathrm{R})$ & $128(\mathrm{R})$ & $2(S)$ \\
\hline Cefuroxime & $>64(\mathrm{R})$ & $8(S)$ & $8(S)$ & $8(S)$ \\
\hline Cefoxitin ${ }^{(*)}$ & $16(\mathrm{I})$ & $8(S)$ & $8(S)$ & $2(S)$ \\
\hline Cefotaxime & $>128(\mathrm{R})$ & $0.5(S)$ & $0.5(S)$ & $0.125(S)$ \\
\hline Ceftazdime & $64(\mathrm{R})$ & $2(\mathrm{I})$ & $4(\mathrm{I})$ & $0.5(S)$ \\
\hline Cefepime & $8(\mathrm{R})$ & $0.25(S)$ & $0.25(S)$ & $<0.06(S)$ \\
\hline Ertapenem & $4(\mathrm{R})$ & $0.25(\mathrm{~S})$ & $0.25(\mathrm{~S})$ & $<0.06(S)$ \\
\hline Imipenem & $2(S)$ & $0.5(S)$ & $0.5(S)$ & $0.125(S)$ \\
\hline Meropenem & $1(S)$ & $0.5(\mathrm{~S})$ & $0.5(\mathrm{~S})$ & $<0.06(S)$ \\
\hline Doripenem ${ }^{(*)}$ & $1(\mathrm{~S})$ & $0.5(\mathrm{~S})$ & $0.5(\mathrm{~S})$ & $<0.06(\mathrm{~S})$ \\
\hline Gentamicin & $128(\mathrm{R})$ & $128(\mathrm{R})$ & $128(\mathrm{R})$ & $0.5(\mathrm{~S})$ \\
\hline Tobramycin & $128(\mathrm{R}$ & $128(\mathrm{R})$ & $128(\mathrm{R})$ & $0.125(S)$ \\
\hline Amikacin & $>128(\mathrm{R})$ & $>128(\mathrm{R})$ & $>128(\mathrm{R})$ & $0.125(S)$ \\
\hline Netilmicin ${ }^{(*)}$ & $>128(\mathrm{R})$ & $128(\mathrm{R})$ & $>128(\mathrm{R})$ & $0.125(S)$ \\
\hline Ciprofloxacin & $4(\mathrm{R})$ & $<0.06(S)$ & $<0.06(\mathrm{~S})$ & $<0.06(\mathrm{~S})$ \\
\hline Levofloxacin & $8(\mathrm{R})$ & $<0.06(\mathrm{~S})$ & $<0.06(\mathrm{~S})$ & $<0.06(\mathrm{~S})$ \\
\hline Tigecycline & $2(\mathrm{R})$ & $0.25(S)$ & $0.125(\mathrm{~S})$ & $<0.06(S)$ \\
\hline Tetracycline ${ }^{(*)}$ & $1(S)$ & $0.5(\mathrm{~S})$ & $1(\mathrm{~S})$ & $0.5(\mathrm{~S})$ \\
\hline Minocycline $^{(*)}$ & $8(\mathrm{I})$ & $4(S)$ & $2(S)$ & $4(S)$ \\
\hline Colistin & $16(\mathrm{R})$ & $0.125(\mathrm{~S})$ & $<0.06(\mathrm{~S})$ & $<0.06(\mathrm{~S})$ \\
\hline Trimethoprim/sulfamethoxazole & $>128(\mathrm{R})$ & $0.125(\mathrm{~S})$ & $0.125(\mathrm{~S})$ & $<0.06(\mathrm{~S})$ \\
\hline Cloramphenicol & $32(\mathrm{R})$ & $8(S)$ & $8(S)$ & $8(S)$ \\
\hline Fosfomycin & $>256(\mathrm{R})$ & $8(S)$ & $8(S)$ & $8(S)$ \\
\hline
\end{tabular}

Pip $^{\text {r }}$ : E. coli $\mathrm{J} 53$ transconjugant selected in MHA supplemented with piperacillin and sodium azide, AK ${ }^{\mathrm{r}}$ : E. coli J53 transconjugant selected in MHA supplemented with amikacin and sodium azide. wt: wild-type strain. R: resistant, I: intermediate, S: susceptible. ${ }^{(*)}$ Clinical and Laboratory Standards Institute (CLSI) breakpoints were applied for these antibiotics.

\subsection{Whole-Genome Sequencing of the XDR K. pneumoniae MS3802}

In order to know in detail the genetic basis of virulence and antimicrobial resistance, the MS3802 genome was fully sequenced. The isolate was confirmed to be K. pneumoniae of capsular serotype K1 and sequence type 23 (ST23) from the well-known hypervirulent clonal complex CC23. MS3002 has a circular chromosome of 5,933,527 bp. It also harbours two plasmids of 234,774 bp (pMS3802-CTXM-vir) and 80,836 bp (pMS3802OXARMA) (Figure 1). The genome GC\% content of MS3802 was 56.95, and 5,717 protein-coding genes were predicted. According to the Virulence Factor Database (VFDB) search, the MS3802 isolate presented 114 virulence-related genes (Table S1). Among these were the chromosomally-encoded yersiniabactin system irp1, irp2, ybtAEPQSTUX and its receptor fyuA, the wcaGHIJ genes related with capsule biosynthesis, the mag $A / w z y \_K$ gene coding for the mucoviscosity-associated protein, all $A B C D$ genes and regulators allS and allR for allantoin metabolism and the type 3 fimbrial genes $m r k A B C D F H I$, all of them usually linked with hypervirulent clones such as ST23. 


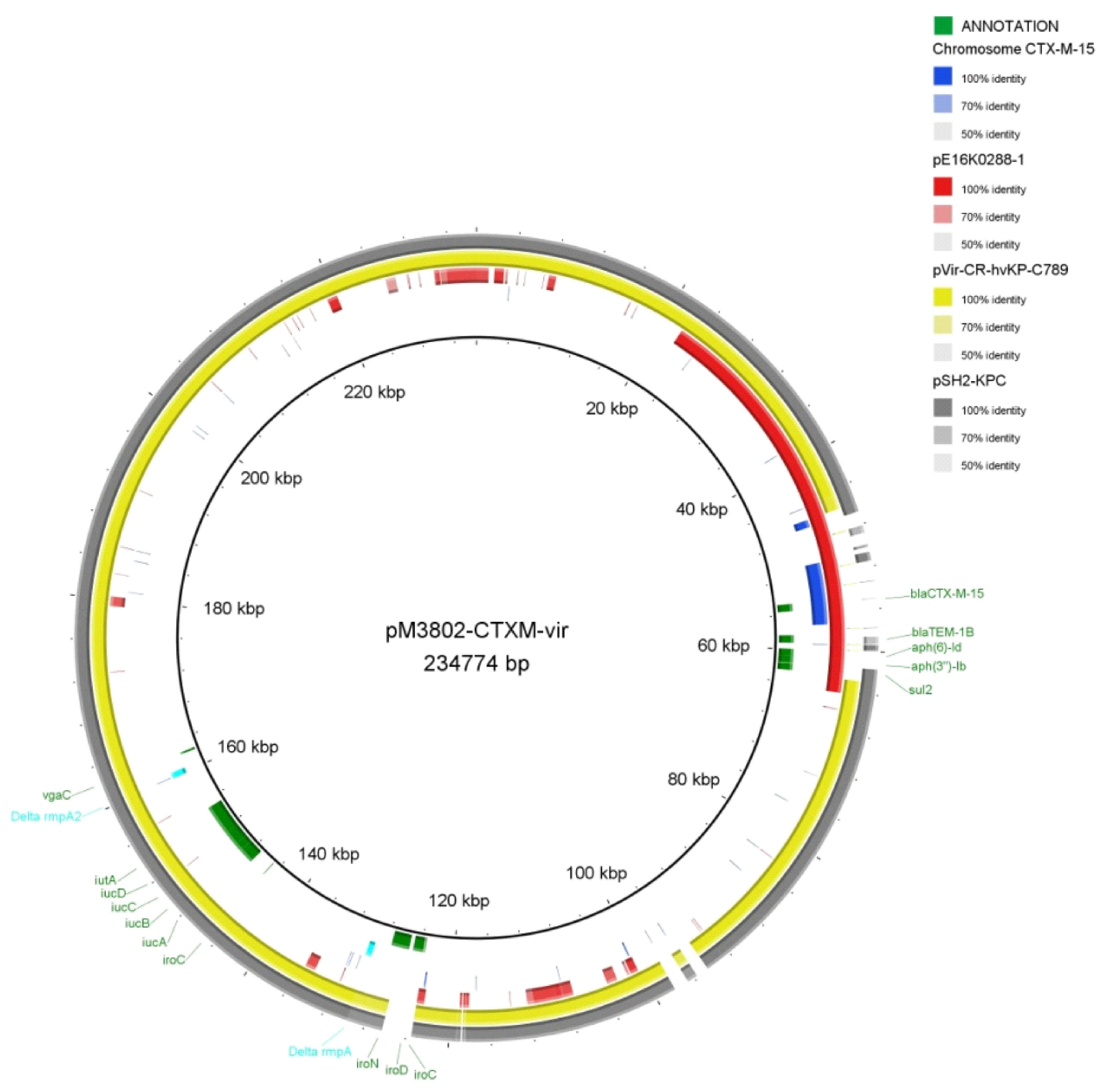

(a)

Figure 1. Cont. 


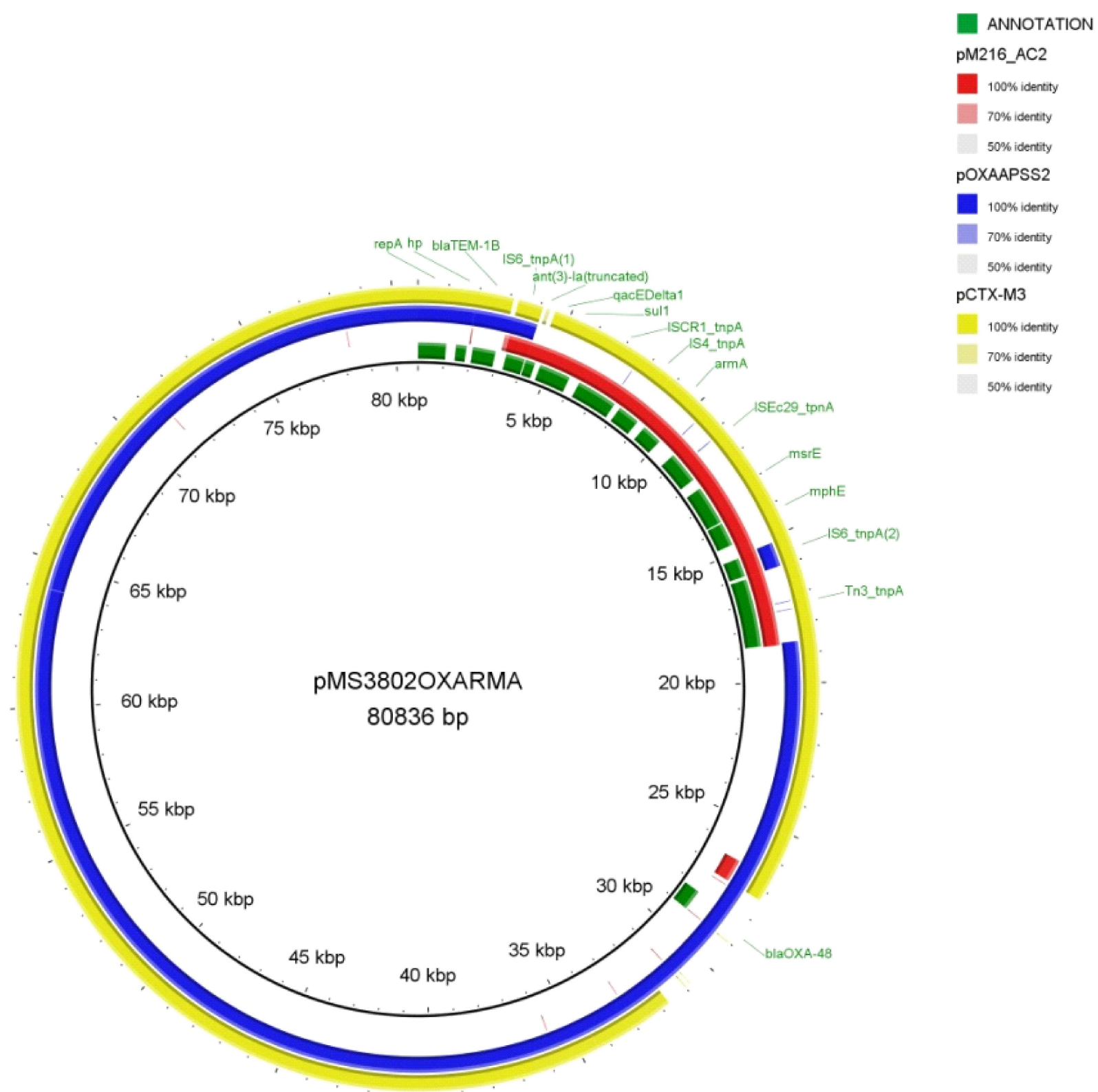

(b)

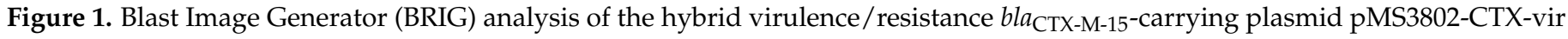
(a) and plasmid pMS3802OXARMA containing the bla $a_{\mathrm{OXA}-48}$ and armA genes (b) found in the XDR K. pneumoniae isolate MS3802. Comparative analysis of plasmids pMS3802-CTX-vir and pMS3802OXARMA with closely related plasmids using the BLAST Ring Image Generator is shown in each case. The concentric rings display similarity between the reference sequence in the inner ring and the other sequences in the outer rings. The different colour levels indicate a BLASTn result with a matched degree of shared regions, as shown to the right of each plasmid rings.

Search for antimicrobial-resistant genes using Resfinder Database identified the presence of the $b l a_{\mathrm{CTX}-\mathrm{M}-15}$ gene flanked by the cupin fold metalloprotein $w b u C$ gene, a Tn3-like, IS6 and ISEc9 transposase coding genes, which are frequently associated with CTX-M-15 (Figure 2A). Genes qnrB1, ant(3")-Ia, dfrA14, fos A, bla $a_{\mathrm{SHV}-190}$ and the multidrug efflux system oqxAB were also present in the chromosome of MS3802.

Other relevant antimicrobial-resistant determinants and virulence factors were found to be plasmid-encoded. The larger plasmid, pMS3802-CTXM-vir, belonged to the incompatibility group IncHI1B, and it is an example of hybrid resistance/virulence plasmid. Hybrid plasmids containing both drug-resistance and virulence-related genes have been recently described $[23,32-35]$. pMS3802-CTXM-vir carried a second copy of the bla $a_{\mathrm{CTX}-\mathrm{M}-15}$ 
gene within the same gene arrangement as the one located in the chromosome IS26-Tn3$w b u C-b l a_{\mathrm{CTX}-\mathrm{M}-15}-\mathrm{ISE} c 9$ (Figure 2A), indicating that $b l a_{\mathrm{CTX}-\mathrm{M}-15}$ was acquired as a result of activities of these mobile genetic elements (MGEs). In particular, ISEc9 (also called ISEcp1) has been shown to be involved in mobilization and dissemination of CTX-M-like enzymes worldwide [36]. The bla $a_{\mathrm{CTX}-\mathrm{M}-15}$ gene, together with other antibiotic resistance genes (bla $a_{\mathrm{TEM}-1}, a p h(6)-I d, a p h\left(3^{\prime \prime}\right)-\mathrm{Ib}$ and sul2), was part of a large antibiotic resistance module (ARM) of 20,782 bp that was bracketed by two copies of the insertion sequence IS5075 inserted in the same orientation with respect to each other (Figure 2A). Within this AMR was also a smaller internal module of 5408 bp flanked by two IS26 elements containing five ORFs with unknown functions (hypothetical proteins) and a C2H2-type zinc finger protein. This module was inserted between a Tn3-like and a Tn21 transposase coding genes (Figure 2A) and was likely acquired through a transposition process. A 13,626 bp fragment from the ARM containing the $b l a_{\mathrm{CTX}-\mathrm{M}-15}$ gene shared a $99.6 \%$ similarity with the backbone of plasmid pE16K0288-1 (GenBank accession number: CP052263.1). Identical direct repeat sequences (ATGGTCACTCCC) were found upstream of each IS5075 copies suggesting that a possible transposition event occurred and led us to identify a new putative composite transposon. One of the IS5075 copies was situated $81 \mathrm{bp}$ upstream of a gene coding for a Tn21-like transposase, which is consistent with what has been previously observed which is that IS5075 targets the terminal inverted repeats of the Tn21-like transposons of the Tn3 family [37].

Plasmid pMS3802-CTXM-vir also encoded some virulence-related genes such as the ferric aerobactin $i u c A B C D$ and aerobactin receptor iut $A$, the salmochelin siderophore iroBCDN and truncated copies of genes encoding the capsular polysaccharide synthesis (CPS) regulators rmpA and rmpA2 (Figure 1A). According to previous studies, deletions of either $r m p A$ or $r m p A 2$ genes resulted in a significant decrease of CPS $[9,10,38]$. The presence of nonfunctional alleles of these genes might be the cause for the absence of the hypermucoviscous phenotype in isolate MS3802. Nevertheless, the occurrence of $r m p A / A 2$ genes in $\mathrm{K} 1$ and $\mathrm{K} 2$ strains and their effect on CPS have been demonstrated to be dependent on the genetic background of each strain [10].

The smaller plasmid found in isolate MS3802, pMS3802OXARMA was an IncM2 type that shared a $99.8 \%$ similarity with the backbone of another IncM2 type plasmid, pOXAAPSS2 (GenBank accession number: KU159086.1) (Figure 1B). pMS3802OXARMA contained the carbapenemase gene $b l a_{\mathrm{OXA}-48}$ carried by a Tn1999-like transposon inserted into the tir gene, encoding a plasmid transfer inhibition protein (Figure 2B). A previous study suggested that disruption of tir was associated with higher conjugation frequencies of bla $a_{\mathrm{OXA}-48}$-bearing plasmids [39]. pMS3802OXARMA was also a carrier of the $16 \mathrm{~S}$ rRNA methylase arm $A$ that confers high resistance levels to aminoglycosides. The armA gen was located adjacent to an ORF coding an unknown protein and the MGEs ISEc28, ISEc29 and ISCR1. The msrE and $m p h E$ macrolide resistance genes were found downstream of the ISEc29 element. Upstream of ISCR1 were detected the genes sul1, qacE $\Delta 1$ and a truncated ant (3")-Ia gene (Figure 2C). All these antimicrobial-resistant determinants were located within a putative class I transposon bounded by two copies of IS26. Downstream of the IS26 positioned on the right side of the putative transposon was a Tn3-transposase gene. The $b l a_{\text {TEM-1 }}$ gene was found upstream of the left side IS26 copy. This gene arrangement was homologous to a Tn1548-like transposon and a gene cluster of 10,733 bp, located on IncM2 and IncA $/ C_{2}$ type plasmids, pCTX-M-3 (GenBank accession number: AF550415.2) and pM216_AC2 (GenBank accession number: AP018145.1), respectively (Figure 2C). This suggests that plasmid pMS3802OXARMA might have acquired this transposon-like structure from a closely related plasmid to PCTX-M-3 or pM216_AC2 via an IS26-mediated gene transfer and that association of armA and other resistance determinants with IS26 found in this gene array could facilitate their introduction into new genetic locations. Both replicative and conservative transposition mediated by IS26-like elements has been demonstrated to be one of the major mechanisms of transmission of antimicrobial resistance determinants [40]. 

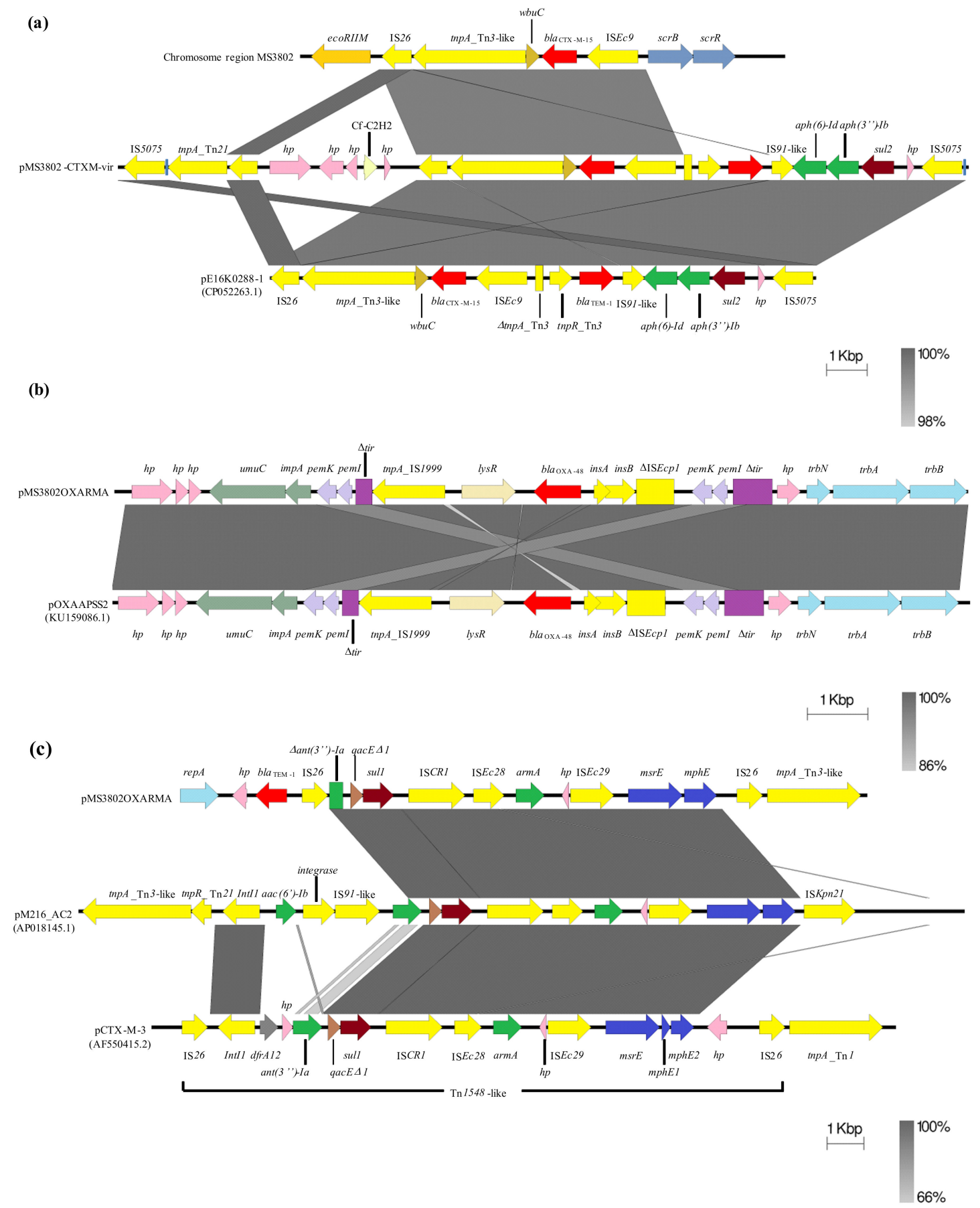

Figure 2. Schematic representation of the genetic location of the $b l a_{\mathrm{CTX}-\mathrm{M}-15}(\mathbf{a}), b l a_{\mathrm{OXA}-48}(\mathbf{b})$ and $\operatorname{armA}(\mathbf{c})$ genes found in the K. pneumoniae isolate MS3802. The respective regions from MS3802 (chromosome or plasmid-encoded) containing $b l a_{\mathrm{CTX}-\mathrm{M}-15}, b l a_{\mathrm{OXA}-48}$ and $a r m A$ are compared with their closest homologous regions present in plasmids pE16K02881(CP052263.1), pOXAAPSS2 (KU159086.1) and pM216_AC2 (AP018145.1) and pCTX-M-3 (AF550415.2). Predicted open reading frames (ORFs) are represented on each lane by coloured arrows, with arrowheads showing the direction of transcription. Genes are highlighted according to similar functions: resistance to beta-lactams (red), aminoglycosides (green), sulfonamides (brown), macrolides (dark blue), mobile genetic elements (MGEs) or gene mobilization-related genes (yellow); ORFs with unknown (hp) functions are in pink, and those with other related functions have the same colour. Nonfunctional ORFs (deleted or disrupted) are represented by boxes. Homologous regions generated by a BLASTn comparison ( $\geq 99 \%$ identity) are represented as gray blocks connected across the strands. Colour shadings indicate the degree of similarity: the more saturated a similarity block, the more conserved are two ORF pairs or DNA regions. Figures were created using the Easyfig software [41]. 


\subsection{Demonstration of Transferability of MS3802 Plasmids}

Conjugation experiments performed with sodium azide Escherichia coli $\mathrm{J} 53\left(\mathrm{Az}^{\mathrm{r}}\right)$ as a recipient strain demonstrated the transferability of the plasmid pMS3802OXARMA at frequencies of $6.9 \times 10^{-4}$ and $3.7 \times 10^{-4}$ (transconjugants per donor) when J53 transconjugants were selected with piperacillin+sodium azide and amikacin+sodium azide, respectively. Transconjugants were selected with two different antibiotics as it was not known whether $b l a_{\mathrm{OXA}-48}, b l a_{\mathrm{CTX}-\mathrm{M}-15}$ and $\operatorname{arm} A$ genes were located in the same plasmid. Antimicrobial susceptibility testing demonstrated that transconjugants exhibited resistance to amoxicillin/clavulanate, piperacillin/tazobactam, gentamicin, tobramycin, amikacin, netilmicin and showed intermediate-resistance to ceftazidime but remained susceptible to the rest of the agents tested (Table 1). PCR using specific primers [42-44] confirmed the presence of the $b a_{\mathrm{OXA}-48}$ and armA genes, but not the ${ }{ }_{\mathrm{CTX}} \mathrm{CT}-15$ in the transconjugants, indicating that conjugation of plasmid pMS3802-CTXM-vir did not take place under the experimental conditions employed. Previous studies showed that hybrid virulence/resistance plasmids could not be transferred to $E$. coli by conjugation [32,45].

\section{Conclusions}

Our findings demonstrated the presence of a new IncHI1B hybrid drug-resistant virulent plasmid bearing the $b l a_{\mathrm{CTX}-\mathrm{M}-15}$ gene as well as a new IncM2 conjugative plasmid harbouring $b a_{\mathrm{OXA}-48}$, arm $A$ and several other antibiotic-resistant determinants, thus mediating multidrug resistance in K. pneumoniae. To the best of our knowledge, this is the first case of an XDR K. pneumoniae of serotype K1 and ST23 from CC23, usually associated with hypervirulence, co-producing CTX-M-15, OXA-48 and ArmA in Spain. Although reports of multidrug carbapenemase-producing hypervirulent $K$. pneumoniae have so far been rare in our country, the occurrence of such isolates is particularly worrisome due to the confluence of both hypervirulence and multidrug resistance. This represents a new challenge clinicians and microbiologists have to overcome as it is a serious threat to public health. In spite of the existence of several studies about hvKp, there is still a paucity of information about multidrug-resistant hvKp, especially those multidrug-resistance strains carrying hybrid virulence/resistant plasmids. Definition of hypervirulence also requires further studies as virulence-related genes associated with hvKp strains are potential targets for new antibiotic treatments. On the other hand, the development of new effective diagnostic methods for the identification of MDR hvKp is urgently needed, as well as enhanced surveillance programs for the detection of such strains should be implemented. More prospective studies are also necessary in order to detect and determine the incidence of multidrug-resistant hvKp isolates in our hospital settings.

\section{Materials and Methods}

\subsection{Strain Identification and Antimicrobial Susceptibility Testing}

The isolate MS3802 was collected from a tracheostomy exudate from a male patient who was involved in a serious motor vehicle accident. Bacterial species identification was performed by using a Vitek-2 instrument (BioMérieux, Marcy l'Etoile, France), and subsequent confirmation was carried out by matrix-assisted laser desorption ionizationtime of flight mass spectrometry (MALDI-TOF/Vitek-MS with SARAMIS MS-IVD v2.0) and by whole-genome sequencing (WGS).

The minimum inhibitory concentration of 27 antimicrobial agents was determined by broth microdilution according to the Clinical and Laboratory Standards Institute (CLSI) guidelines [46]. The EUCAST 2020 susceptibility breakpoints were applied (www.eucast. org/clinical_breakpoints/), except for cefoxitin, doripenem, netilmicin, minocyclin and tetracyclin, for which CLSI breakpoints were employed. Pseudomonas aeruginosa ATCC 27853, Escherichia coli ATCC 25,922 and Klebsiella quasipneumoniae subsp. similipneumoniae ATCC 700,603 were used as control strains for antimicrobial susceptibility testing. 


\subsection{String Test}

In order to see if isolate MS3802 showed a hypermucoviscous phenotype, the string test was performed as described before [11]. A disposable inoculation loop was used to stretch away a bacterial colony grown on the agar plate. The formation of a viscous string $>5 \mathrm{~mm}$ in length is defined as string test-positive, otherwise, the isolate was classified as mucoid.

\subsection{Whole-Genome Sequencing and Bioinformatics Analysis}

Genomic DNA from K. pneumoniae MS3802 isolate was purified with the DNeasy Blood \& Tissue Kit (Qiagen) and sequenced by using both Illumina MiSeq instrument using reagents kit v3 for $2 \times 300$ paired-end libraries (Illumina, San Diego, CA, USA) as previously described [47] and Oxford Nanopore MinION (Oxford Nanopore Technologies (ONT), UK). Raw reads from the sequencing platform were directly analyzed by using an in-house bioinformatics pipeline [48] and the genome of K. pneumoniae subsp. pneumoniae ATCC 700721/MGH 78,578 as a reference strain. The options used in this study included quality control and filtering of the reads [49-51], genome assembly with SPAdes [52] and Quast [53], genome annotation with Prokka [54] and multi-locus sequence typing (MLST, T. Seemann, https:/ / github.com/tseemann/mLst). Search of antibiotic resistance genes, virulence genes and plasmid replicons was done using BLAST [55] and ABRicate (T. Seemann https:/ /github.com/tseemann/abricate) against ResFinder [56], Virulence Factor Database (VFDB) [57] and PlasmidFinder [58] databases, respectively. Point mutation investigation was performed with PointFinder [59]. Pangenome was created with Roary [60] and FastTree [61]. Serotyping was performed using Kaptive software [62].

\subsection{Conjugation Experiments}

The transferability of plasmids was investigated by carrying out conjugation experiments. K. pneumoniae MS3802 was used as a donor and E. coli J53, resistant to sodium azide $\left(A z^{r}\right)$, was used as the recipient strain. Transconjugants were selected on MacConkey agar plates supplemented with piperacillin $(50 \mu \mathrm{g} / \mathrm{mL})$ or amikacin $(40 \mu \mathrm{g} / \mathrm{mL})$ and sodium azide $(100 \mu \mathrm{g} / \mathrm{mL})$. Transconjugants were confirmed by PCR with specific primers for amplification of bla $a_{\mathrm{OXA}-48}$, and CTX-M-encoding genes [42] and $\operatorname{armA}$ [43], as well as susceptibility testing (Table 1).

\subsection{Nucleotide Accession Numbers}

The whole-genome sequencing reads and annotated assembly of K. pneumoniae MS3802 and plasmids pMS3802-CTXM-vir and pMS3802OXARMA are available under the BioProject ID PRJNA674482 and GenBank accession numbers W222482 and MW222483, respectively.

Supplementary Materials: The following are available online at https:/ / www.mdpi.com/2079-638 2/10/2/157/s1, Table S1: Virulence and antimicrobial resistance genes of isolate MS3802.

Author Contributions: L.L.-U. and M.D.F.S. isolated and performed the previous antimicrobial susceptibility tests of MS3802 isolate.; M.H., J.M.E. and A.A.O.-S. designed the study; M.H. performed sequencing experiments, bioinformatics analysis and wrote the paper; A.A.O.-S. performed reference susceptibility testing, string tests, conjugation experiments, bioinformatics analyses and wrote and edited the paper; D.A. performed genome assembly and bioinformatics analysis; J.M.E. acquired funding and edited the paper. All authors have read and agreed to the published version of the manuscript.

Funding: This research was funded by the "Gerencia Regional de Salud de la Consejería de Sanidad de la Junta de Castilla y León" [grant number GRS1780/A/18], the Spanish Ministry of Economy and Competitiveness (MINECO) [grant number AGL2016-74882-C3), the "Plan Nacional de I+ D + i", Subdirección General de Redes y Centros de Investigación Cooperativa, and the Spanish Network for Research in Infectious Diseases REIPI RD16/0016 co-financed by the European Development Regional Fund "A way to achieve Europe" ERDF. 
Data Availability Statement: The data presented in this study regarding the information about both the virulence and antimicrobial resistant genes are in Supplementary Table S1. Genome and plasmid sequences are available in https: / www.ncbi.nlm.nih.gov/bioproject/ under the BioProject ID PRJNA674482 and GenBank accession numbers W222482 and MW222483, respectively.

Conflicts of Interest: The other authors have no conflict of interest to disclose.

\section{References}

1. Hamzaoui, Z.; Ocampo-Sosa, A.; Fernandez Martinez, M.; Landolsi, S.; Ferjani, S.; Maamar, E.; Saidani, M.; Slim, A.; MartinezMartinez, L.; Boutiba-Ben Boubaker, I. Role of association of OmpK35 and OmpK36 alteration and blaESBL and/or blaAmpC genes in conferring carbapenem resistance among non-carbapenemase-producing Klebsiella pneumoniae. Int. J. Antimicrob. Agents 2018, 52, 898-905. [CrossRef]

2. Liu, Y.C.; Cheng, D.L.; Lin, C.L. Klebsiella pneumoniae liver abscess associated with septic endophthalmitis. Arch. Intern. Med. 1986, 146, 1913-1916. [CrossRef]

3. Lin, F.; Xu, Y.; Chang, Y.; Liu, C.; Jia, X.; Ling, B. Molecular Characterization of Reduced Susceptibility to Biocides in Clinical Isolates of Acinetobacter baumannii. Front. Microbiol. 2017, 8, 1836. [CrossRef]

4. Cubero, M.; Grau, I.; Tubau, F.; Pallarés, R.; Dominguez, M.A.; Liñares, J.; Ardanuy, C. Hypervirulent Klebsiella pneumoniae clones causing bacteraemia in adults in a teaching hospital in Barcelona, Spain (2007-2013). Clin. Microbiol. Infect. 2016, $22,154-160$. [CrossRef]

5. Sánchez-López, J.; García-Caballero, A.; Navarro-San Francisco, C.; Quereda, C.; Ruiz-Garbajosa, P.; Navas, E.; Dronda, F.; Morosini, M.I.; Cantón, R.; Diez-Aguilar, M. Hypermucoviscous Klebsiella pneumoniae: A challenge in community acquired infection. IDCases 2019, 17, e00547. [CrossRef]

6. Cubero, M.; Marti, S.; Domínguez, M.Á.; González-Díaz, A.; Berbel, D.; Ardanuy, C. Hypervirulent Klebsiella pneumoniae serotype $\mathrm{K} 1$ clinical isolates form robust biofilms at the air-liquid interface. PLoS ONE 2019, 14, e0222628. [CrossRef]

7. Fang, C.-T.; Chuang, Y.-P.; Shun, C.-T.; Chang, S.-C.; Wang, J.-T. A novel virulence gene in Klebsiella pneumoniae strains causing primary liver abscess and septic metastatic complications. J. Exp. Med. 2004, 199, 697-705. [CrossRef]

8. Yeh, K.-M.; Chang, F.-Y.; Fung, C.-P.; Lin, J.-C.; Siu, L.K. magA is not a specific virulence gene for Klebsiella pneumoniae strains causing liver abscess but is part of the capsular polysaccharide gene cluster of K. pneumoniae serotype K1. J. Med. Microbiol. 2006, 55, 803-804. [CrossRef]

9. $\quad$ Cheng, H.Y.; Chen, Y.S.; Wu, C.Y.; Chang, H.Y.; Lai, Y.C.; Peng, H.L. RmpA Regulation of Capsular Polysaccharide Biosynthesis in Klebsiella pneumoniae CG43. J. Bacteriol. 2010, 192, 3144-3158. [CrossRef]

10. Hsu, C.-R.; Lin, T.-L.; Chen, Y.-C.; Chou, H.-C.; Wang, J.-T. The role of Klebsiella pneumoniae rmpA in capsular polysaccharide synthesis and virulence revisited. Microbiology 2011, 157, 3446-3457. [CrossRef]

11. Shon, A.S.; Bajwa, R.P.S.; Russo, T.A. Hypervirulent (hypermucoviscous) Klebsiella pneumoniae: A new and dangerous breed. Virulence 2013, 4, 107-118. [CrossRef]

12. Catalán-Nájera, J.C.; Garza-Ramos, U.; Barrios-Camacho, H. Hypervirulence and hypermucoviscosity: Two different but complementary Klebsiella spp. phenotypes? Virulence 2017, 8, 1111-1123. [CrossRef]

13. Struve, C.; Roe, C.C.; Stegger, M.; Stahlhut, S.G.; Hansen, D.S.; Engelthaler, D.M.; Andersen, P.S.; Driebe, E.M.; Keim, P.; Krogfelt, K.A. Mapping the evolution of hypervirulent Klebsiella pneumoniae. MBio 2015, 6. [CrossRef]

14. Wyres, K.L.; Wick, R.R.; Gorrie, C.; Jenney, A.; Follador, R.; Thomson, N.R.; Holt, K.E. Identification of Klebsiella capsule synthesis loci from whole genome data. Microb. Genom. 2016, 2, e000102. [CrossRef]

15. Choby, J.E.; Howard-Anderson, J.; Weiss, D.S. Hypervirulent Klebsiella pneumoniae_Clinical and molecular perspectives. J. Intern. Med. 2019. [CrossRef]

16. Brisse, S.; Fevre, C.; Passet, V.; Issenhuth-Jeanjean, S.; Tournebize, R.; Diancourt, L.; Grimont, P. Virulent clones of Klebsiella pneumoniae: Identification and evolutionary scenario based on genomic and phenotypic characterization. PLoS ONE 2009, 4, e4982. [CrossRef]

17. Bialek-Davenet, S.; Criscuolo, A.; Ailloud, F.; Passet, V.; Jones, L.; Delannoy-Vieillard, A.-S.; Garin, B.; Le Hello, S.; Arlet, G.; Nicolas-Chanoine, M.-H.; et al. Genomic definition of hypervirulent and multidrug-resistant Klebsiella pneumoniae clonal groups. Emerg. Infect. Dis. 2014, 20, 1812-1820. [CrossRef]

18. Zhang, Y.; Zhao, C.; Wang, Q.; Wang, X.; Chen, H.; Li, H.; Zhang, F.; Li, S.; Wang, R.; Wang, H. High prevalence of hypervirulent Klebsiella pneumoniae infection in China: Geographic distribution, clinical characteristics, and antimicrobial resistance. Antimicrob. Agents Chemother. 2016, 60, 6115-6120. [CrossRef]

19. Chew, K.L.; Lin, R.T.P.; Teo, J.W.P. Klebsiella pneumoniae in Singapore: Hypervirulent infections and the carbapenemase threat. Front. Cell. Infect. Microbiol. 2017, 7. [CrossRef]

20. Dong, N.; Yang, X.; Zhang, R.; Chan, E.W.C.; Chen, S. Tracking microevolution events among ST11 carbapenemase-producing hypervirulent Klebsiella pneumoniae outbreak strains. Emerg. Microbes Infect. 2018, 7. [CrossRef]

21. Karlsson, M.; Stanton, R.A.; Ansari, U.; McAllister, G.; Chan, M.Y.; Sula, E.; Grass, J.E.; Duffy, N.; Anacker, M.L.; Witwer, M.L.; et al. Identification of a carbapenemase-producing hypervirulent Klebsiella pneumoniae isolate in the United States. Antimicrob. Agents Chemother. 2019, 63. [CrossRef] 
22. Qu, T.; Zhou, J.; Jiang, Y.; Shi, K.; Li, B.; Shen, P.; Wei, Z.; Yu, Y. Clinical and microbiological characteristics of Klebsiella pneumoniae liver abscess in East China. BMC Infect. Dis. 2015, 15, 161. [CrossRef]

23. Turton, J.; Davies, F.; Turton, J.; Perry, C.; Payne, Z.; Pike, R. Hybrid resistance and virulence plasmids in "high-risk" clones of Klebsiella pneumoniae, including those carrying blandm-5. Microorganisms 2019, 7, 326. [CrossRef]

24. Mataseje, L.F.; Boyd, D.A.; Mulvey, M.R.; Longtin, Y. Two Hypervirulent Klebsiella pneumoniae isolates producing a blaKPC-2 carbapenemase from a canadian patient. Antimicrob. Agents Chemother. 2019, 63. [CrossRef]

25. Shu, L.; Dong, N.; Lu, J.; Zheng, Z.; Hu, J.; Zeng, W.; Sun, Q.; Chan, E.W.C.; Zhou, H.; Hu, F.; et al. Emergence of OXA-232 Carbapenemase-Producing Klebsiella pneumoniae That Carries a pLVPK-Like Virulence Plasmid among Elderly Patients in China. Antimicrob. Agents Chemother. 2019, 63. [CrossRef]

26. Liu, Y.; Long, D.; Xiang, T.-X.; Du, F.-L.; Wei, D.D.; Wan, L.-G.; Deng, Q.; Cao, X.-W.; Zhang, W. Whole genome assembly and functional portrait of hypervirulent extensively drug-resistant NDM-1 and KPC-2 co-producing Klebsiella pneumoniae of capsular serotype K2 and ST86. J. Antimicrob. Chemother. 2019, 74, 1233-1240. [CrossRef]

27. Chen, Y.T.; Chang, H.Y.; Lai, Y.C.; Pan, C.C.; Tsai, S.F.; Peng, H.L. Sequencing and analysis of the large virulence plasmid pLVPK of Klebsiella pneumoniae CG43. Gene 2004, 337, 189-198. [CrossRef]

28. Wu, K.-M.; Li, L.-H.; Yan, J.-J.; Tsao, N.; Liao, T.-L.; Tsai, H.-C.; Fung, C.-P.; Chen, H.-J.; Liu, Y.-M.; Wang, J.-T.; et al. Genome sequencing and comparative analysis of Klebsiella pneumoniae NTUH-K2044, a strain causing liver abscess and meningitis. J. Bacteriol. 2009, 191, 4492-4501. [CrossRef]

29. Lee, C.-R.; Lee, J.H.; Park, K.S.; Jeon, J.H.; Kim, Y.B.; Cha, C.-J.; Jeong, B.C.; Lee, S.H. Antimicrobial Resistance of Hypervirulent Klebsiella pneumoniae: Epidemiology, Hypervirulence-Associated Determinants, and Resistance Mechanisms. Front. Cell. Infect. Microbiol. 2017, 7, 483. [CrossRef]

30. Magiorakos, A.-P.; Srinivasan, A.; Carey, R.B.; Carmeli, Y.; Falagas, M.E.; Giske, C.G.; Harbarth, S.; Hindler, J.F.; Kahlmeter, G.; Olsson-Liljequist, B.; et al. Multidrug-resistant, extensively drug-resistant and pandrug-resistant bacteria: An international expert proposal for interim standard definitions for acquired resistance. Clin. Microbiol. Infect. 2012, 18, 268-281. [CrossRef]

31. Wang, C.H.; Lu, P.L.; Liu, E.Y.M.; Chen, Y.Y.; Lin, F.M.; Lin, Y.T.; Chang, F.Y.; Lin, J.C. Rapid identification of capsular serotype $\mathrm{K} 1 / \mathrm{K} 2$ Klebsiella pneumoniae in pus samples from liver abscess patients and positive blood culture samples from bacteremia cases via an immunochromatographic strip assay. Gut Pathog. 2019, 11. [CrossRef]

32. Dong, N.; Lin, D.; Zhang, R.; Chan, E.W.C.; Chen, S. Carriage of bla KPC-2 by a virulence plasmid in hypervirulent Klebsiella pneumoniae. J. Antimicrob. Chemother. 2018, 73, 3317-3321. [CrossRef]

33. Shen, D.; Ma, G.; Li, C.; Jia, X.; Qin, C.; Yang, T.; Wang, L.; Jiang, X.; Ding, N.; Zhang, X.; et al. Emergence of a MultidrugResistant Hypervirulent Klebsiella pneumoniae Sequence Type 23 Strain with a Rare blaCTX-M-24-Harboring Virulence Plasmid. Antimicrob. Agents Chemother. 2019, 63. [CrossRef]

34. Zhang, Y.; Jin, L.; Ouyang, P.; Wang, Q.; Wang, R.; Wang, J.; Gao, H.; Wang, X.; Wang, H. Evolution of hypervirulence in carbapenem-resistant Klebsiella pneumoniae in China: A multicentre, molecular epidemiological analysis. J. Antimicrob. Chemother. 2020, 75, 327-336. [CrossRef]

35. Xie, M.; Chen, K.; Ye, L.; Yang, X.; Xu, Q.; Yang, C.; Dong, N.; Chan, E.W.C.; Sun, Q.; Shu, L.; et al. Conjugation of Virulence Plasmid in Clinical Klebsiella pneumoniae Strains through Formation of a Fusion Plasmid. Adv. Biosyst. 2020, 4, 1900239. [CrossRef]

36. Zhao, W.H.; Hu, Z.Q. Epidemiology and genetics of CTX-M extended-spectrum $\beta$-lactamases in Gram-negative bacteria. Crit. Rev. Microbiol. 2013, 39, 79-101. [CrossRef]

37. Partridge, S.R.; Hall, R.M. The IS1111 Family Members IS4321 and IS5075 Have Subterminal Inverted Repeats and Target the Terminal Inverted Repeats of Tn21 Family Transposons. J. Bacteriol. 2003, 185, 6371-6384. [CrossRef]

38. Lin, T.H.; Wu, C.C.; Kuo, J.T.; Chu, H.F.; Lee, D.Y.; Lin, C.T. Fnr-dependent rmpa and rmpa2 regulation of capsule polysaccharide biosynthesis in Klebsiella pneumoniae. Front. Microbiol. 2019, 10. [CrossRef]

39. Potron, A.; Poirel, L.; Nordmann, P. Derepressed transfer properties leading to the efficient spread of the plasmid encoding carbapenemase OXA-48. Antimicrob. Agents Chemother. 2014, 58, 467-471. [CrossRef]

40. Harmer, C.J.; Moran, R.A.; Hall, R.M. Movement of IS26-Associated antibiotic resistance genes occurs via a translocatable unit that includes a single IS26 and preferentially inserts adjacent to another IS26. MBio 2014, 5. [CrossRef]

41. Sullivan, M.J.; Petty, N.K.; Beatson, S.A. Easyfig: A genome comparison visualizer. Bioinformatics 2011, 27, 1009-1010. [CrossRef]

42. Kalpoe, J.S.; Al Naiemi, N.; Poirel, L.; Nordmann, P. Detection of an ambler class d oxa-48-type $\beta$-lactamase in a Klebsiella pneumoniae strain in the netherlands. J. Med. Microbiol. 2011, 60, 677-678. [CrossRef]

43. Galani, I.; Souli, M.; Panagea, T.; Poulakou, G.; Kanellakopoulou, K.; Giamarellou, H. Prevalence of $16 \mathrm{~S}$ rRNA methylase genes in Enterobacteriaceae isolates from a Greek University Hospital. Clin. Microbiol. Infect. 2012, 18. [CrossRef]

44. Pagani, L.; Dell'Amico, E.; Migliavacca, R.; D’Andrea, M.M.; Giacobone, E.; Amicosante, G.; Romero, E.; Rossolini, G.M. Multiple CTX-M-type extended-spectrum $\beta$-lactamases in nosocomial isolates of Enterobacteriaceae from a hospital in Northern Italy. J. Clin. Microbiol. 2003, 41, 4264-4269. [CrossRef]

45. Xie, M.; Dong, N.; Chen, K.; Yang, X.; Ye, L.; Chan, E.W.C.; Zhang, R.; Chen, S. A hybrid plasmid formed by recombination of a virulence plasmid and a resistance plasmid in Klebsiella pneumoniae. J. Glob. Antimicrob. Resist. 2020, 23, 466-470. [CrossRef]

46. CLSI. Performance Standards for Antimicrobial Susceptibility Testing, 28th ed.; CLSI Supplement M100; Clinical and Laboratory Standards Institute: Wayne, PA, USA, 2018; ISBN 1-56238-839-8. 
47. Hernández, M.; Iglesias, M.R.; Rodríguez-Lázaro, D.; Gallardo, A.; Quijada, N.M.; Miguela-Villoldo, P.; Campos, M.J.; Píriz, S.; López-Orozco, G.; de Frutos, C.; et al. Co-occurrence of colistin-resistance genes mcr-1 and mcr-3 among multidrug-resistant Escherichia coli isolated from cattle, Spain, September 2015. Eurosurveillance 2017, 22. [CrossRef]

48. Quijada, N.M.; Rodríguez-Lázaro, D.; Eiros, J.M.; Hernández, M. TORMES: An automated pipeline for whole bacterial genome analysis. Bioinformatics 2019. [CrossRef]

49. Bolger, A.M.; Lohse, M.; Usadel, B. Trimmomatic: A flexible trimmer for Illumina sequence data. Bioinformatics 2014, 30, 2114-2120. [CrossRef]

50. Schmieder, R.; Edwards, R. Quality control and preprocessing of metagenomic datasets. Bioinformatics 2011, $27,863-864$. [CrossRef]

51. Wood, D.E.; Salzberg, S.L. Kraken: Ultrafast metagenomic sequence classification using exact alignments. Genome Biol. 2014, 15, R46. [CrossRef]

52. Bankevich, A.; Nurk, S.; Antipov, D.; Gurevich, A.A.; Dvorkin, M.; Kulikov, A.S.; Lesin, V.M.; Nikolenko, S.I.; Pham, S.; Prjibelski, A.D.; et al. SPAdes: A new genome assembly algorithm and its applications to single-cell sequencing. J. Comput. Biol. 2012, 19, 455-477. [CrossRef]

53. Gurevich, A.; Saveliev, V.; Vyahhi, N.; Tesler, G. QUAST: Quality assessment tool for genome assemblies. Bioinformatics 2013, 29, 1072-1075. [CrossRef]

54. Seemann, T. Prokka: Rapid prokaryotic genome annotation. Bioinformatics 2014, 30, 2068-2069. [CrossRef]

55. Camacho, C.; Coulouris, G.; Avagyan, V.; Ma, N.; Papadopoulos, J.; Bealer, K.; Madden, T.L. BLAST+: Architecture and applications. BMC Bioinformatics 2009, 10, 421. [CrossRef]

56. Zankari, E.; Hasman, H.; Cosentino, S.; Vestergaard, M.; Rasmussen, S.; Lund, O.; Aarestrup, F.M.; Larsen, M.V. Identification of acquired antimicrobial resistance genes. J. Antimicrob. Chemother. 2012, 67, 2640-2644. [CrossRef]

57. Chen, L.; Yang, J.; Yu, J.; Yao, Z.; Sun, L.; Shen, Y.; Jin, Q. VFDB: A reference database for bacterial virulence factors. Nucleic Acids Res. 2005. [CrossRef]

58. Carattoli, A.; Zankari, E.; Garciá-Fernández, A.; Larsen, M.V.; Lund, O.; Villa, L.; Aarestrup, F.M.; Hasman, H. In Silico detection and typing of plasmids using plasmidfinder and plasmid multilocus sequence typing. Antimicrob. Agents Chemother. 2014, 58, 3895-3903. [CrossRef]

59. Zankari, E.; Allesøe, R.; Joensen, K.G.; Cavaco, L.M.; Lund, O.; Aarestrup, F.M. PointFinder: A novel web tool for WGS-based detection of antimicrobial resistance associated with chromosomal point mutations in bacterial pathogens. J. Antimicrob. Chemother. 2017, 72, 2764-2768. [CrossRef]

60. Page, A.J.; Cummins, C.A.; Hunt, M.; Wong, V.K.; Reuter, S.; Holden, M.T.G.; Fookes, M.; Falush, D.; Keane, J.A.; Parkhill, J. Roary: Rapid large-scale prokaryote pan genome analysis. Bioinformatics 2015, 31, 3691-3693. [CrossRef]

61. Price, M.N.; Dehal, P.S.; Arkin, A.P. Fasttree: Computing large minimum evolution trees with profiles instead of a distance matrix. Mol. Biol. Evol. 2009, 26, 1641-1650. [CrossRef]

62. Wick, R.R.; Heinz, E.; Holt, K.E.; Wyres, K.L. Kaptive web: User-Friendly capsule and lipopolysaccharide serotype prediction for Klebsiella genomes. J. Clin. Microbiol. 2018, 56. [CrossRef] 